\title{
PERSONAL EPISTEMOLOGIES OF STATISTICIANS IN ACADEMIA: AN EXPLORATORY STUDY
}

\author{
AUREL H. DIAMOND \\ The Hebrew University of Jerusalem \\ aurel.diamond@mail.huji.ac.il \\ ANDREAS J. STYLIANIDES \\ University of Cambridge \\ as899@cam.ac.uk
}

\begin{abstract}
In this exploratory study, we investigated the personal epistemologies of statisticians in academia with the aim of offering some insight into what might be an availing epistemology for learning statistics. Findings from in-depth, semi-structured interviews with six academics in the UK currently researching within the field of statistics showed that their statistical personal epistemologies were consistent with constructivist theories of learning. Based on these findings, we proposed an integrated model to represent participants' beliefs about knowledge and knowing in statistics. Furthermore, we found differences between participants' mathematical and statistical personal epistemologies, and we offered an argument for domain-specificity of personal epistemologies. The implications of our findings for research in statistics education and statistical misconceptions are discussed.
\end{abstract}

Keywords: Statistics education research; Statistical misconceptions; Statistics vs. mathematics; University

\section{INTRODUCTION}

Misconceptions of statistical information and data are far too common. Research has indicated that students have difficulty understanding concepts relating to probability distributions (Ben-Zvi, 2004; Hammerman \& Rubin, 2004), measures of variability (delMas \& Liu, 2005; Garfield, 1995), sampling variation (delMas, Garfield, Ooms, \& Chance, 2007; Reading \& Shaughnessy, 2004), statistical inference (Castro Sotos, Vanhoof, Van den Noortgate, \& Onghema, 2007), amongst others (for a summary of research in statistical misconceptions, see Garfield \& Ben-Zvi, 2007). Although instruction can improve students' understanding of these concepts (Meletiou-Mavrotheris \& Lee, 2002; Sedlmeier, 1999), it is not always effective (Chance, delMas, \& Garfield, 2004). One study even showed instruction to have a negative effect on students' conceptual understanding of certain topics in statistics (delMas et al., 2007). Although misconceptions of knowledge exist across all disciplines, the issue seems to be especially pointed within statistics. This begs the question — what is it about statistics that makes it so difficult?

Gaining insight into what makes learning difficult for students is a complicated task that has been approached in many ways. One of these ways relates to personal epistemologies. There is ample evidence to suggest that the epistemology of an individual - that is, their beliefs about knowledge and knowing — can affect how they come to learn

Statistics Education Research Journal, 16(2), 335-361, http://iase-web.org/Publications.php?p=SERJ

C. International Association for Statistical Education (IASE/ISI), November, 2017 
(e.g., Ernest, 2011; Hofer, 2000, 2004a; King \& Kitchener, 1994, 2004; Pajares, 1992). The underlying idea is not that there is an objectively 'correct' way about understanding knowledge, but that there are certain epistemological beliefs that can be more conducive to learning (Muis, 2004). Thus, in order to offer some insight into why misconceptions are so rife in statistics, it would be helpful to identify what kind of beliefs about knowledge and knowing in statistics avail to a sophisticated understanding of the subject.

Our aim in this paper is to begin to characterize what such an availing statistical epistemology might be. Many studies have noted that statistical misconceptions are still held by both advanced university students and experienced researchers outside of statistics (delMas et al., 2007; King \& Kitchener, 1994), so in order to characterize such an epistemology, we focused on the beliefs of academics who are considered to be experts in statistics. This study differs from previous epistemological research relating to statistics education, because studies in the past have been non-empirical (Helmer \& Rescher, 1959; Olsen \& Morgan, 2005), specific to probabilistic thinking (Konold, 1989, 1991), or have focused on the beliefs of students or teachers (Garfield, 1995; Garfield \& Ben-Zvi, 2007; Shaughnessy, 2003). This study was therefore exploratory in nature, even though epistemological research within education and educational psychology is well developed.

Specifically, in this paper we sought to identify main characteristics of the personal epistemologies of statisticians in academia and to match these personal epistemologies to existing models in the literature. Furthermore, given the inextricable link between statistics and mathematics, and the way in which statistics teaching is frequently embedded in mathematics, we also sought to explore similarities and differences between the statistical and mathematical epistemologies of statisticians in academia. Using in-depth, semistructured interviews with six statisticians in academia, we aimed to address the following research questions:

1. What are some main characteristics of the personal epistemologies of statisticians in academia, and how do they relate to existing models of personal epistemologies in the literature?

2. What are similarities and differences between the statistical and mathematical epistemologies of statisticians in academia?

As a background for the paper, in the following section we review research on personal epistemologies in the context of statistics education.

\section{PERSONAL EPISTEMOLOGIES IN THE CONTEXT OF STATISTICS EDUCATION}

The beliefs that individuals have about knowledge and knowing have been the focus of a number of research studies, including studies on epistemological beliefs (Liu \& Liu, 2011; Schommer, 1990, 1998), epistemological theories (Hofer \& Pintrich, 1997; Piaget, 1972), epistemic beliefs (Buehl \& Alexander, 2001), epistemic dimensions (Op 't Eynde, De Corte, \& Verschaffel, 2006), ways of understanding (Confrey \& Kazak, 2006), and many others. Although different terms have been used in these research studies, they all answer questions about what knowledge is and how it is acquired, and can be viewed as parts of the broader body of research on personal epistemology (Hofer, 2000, 2001, 2004b). The term personal epistemology has been used loosely in the past and has not always been defined. For the purpose of this paper, personal epistemology is understood to be the field concerning an individual's beliefs about knowledge and knowing.

The relationship between personal epistemology and education can be viewed through three general paradigms. The first maintains that epistemology is developmental and that a partial goal of education is to foster epistemological development (Finch \& Cumming, 
1998; Perry, 1970). Within statistics education, this paradigm is reflected in a study by delMas et al. (2007) which tracked the conceptual development in statistics of university students throughout a fixed time period. Although the study evaluated the conceptual understanding of the students, and not their personal epistemologies, it illustrates that the epistemological development of students is central to improving understanding in statistics.

The second paradigm upholds that personal epistemology exists in the form of beliefs, and that the learning of an individual is shaped heavily by his or her beliefs (Schommer, 1998). For example, Schommer, Crouse, and Rhodes (1992) found that a student's ability to understand a statistical passage was strongly negatively correlated with a belief that knowledge is discrete. The importance of beliefs about statistics was also emphasized by Garfield (1995) who claimed that statistics becomes difficult for students to learn when ideas about the subject are in conflict with students' own beliefs and intuitions about data and chance.

The final paradigm claims that epistemological beliefs exist as a set of resources (like published books or authoritative figures) and theories about knowledge and knowing. In this case, knowing which resources and theories are activated in a statistical learning context could help educators to better understand and address the sources of statistical misconceptions. Under this paradigm, research has suggested that the understanding of resources is context-dependent (Hofer, 2001). For example, individuals have been known to perceive knowledge as subjective in a statistical context, but as entirely objective if it is in a mathematical context (Olsen \& Morgan, 2005).

The aforementioned paradigms are congruous to three categories of epistemological models, as described below.

\subsection{EPISTEMOLOGICAL MODELS}

Developmental and cognitive models The bases of all developmental models of personal epistemology are a series of longitudinal studies that analyzed interview data to document changes in students' thinking throughout their education and beyond. In the seminal work of Perry (1970), extensive interviews with male students at Harvard University during the 1950s and 1960s helped document the students developing their views of knowledge and learning. The development was characterized by nine steps, the first of which represented a dualistic, absolutist view of knowledge, and the final step, indicative of a realistic view of knowledge, represented an understanding that new information may cause one's position to change. The main contribution of this study was the understanding that a student's view of knowledge better explained their experiences of learning than motivation study skills or ability — myths, according to Moore (2002), that still exist today.

More recent studies have discerned that all individuals follow the same basic developmental sequence, regardless of gender or background, and that any subtle differences within early development stages dissipate after the end of formal education (Baxter Magolda, 2002; Belenky, Clinchy, Goldberger, \& Tarule, 1986). Implicit in these models is the viewpoint that epistemological development is the purpose of education, so developmental models can be understood as being parallel to the first paradigm of the relationship between personal epistemology and education.

From the developmental models emerged cognitive models for personal epistemology. Like their predecessors, cognitive models also describe a move from absolutist, positivist thinking to a more relativist, contextualized approach to knowledge (Kuhn, 1991). The major difference is that these theories attempt to validate developmental models by using structured interviews with standardized evaluation processes to characterize the 
epistemological thinking of an individual. For example, King and Kitchener (2004) developed The Reflective Judgment Model, which uses three levels to categorize student reasoning. Within the first, or pre-reflective level, knowledge is viewed as certain, and correct answers are always assumed to exist. This is followed by the quasi-reflective level, which indicates the recognition of uncertainty and a growing awareness of how knowledge is constructed. The final, or reflective level, was characterized by the ability to place knowledge in context, and the willingness to re-evaluate perspectives on receiving new information.

Multidimensional models Although there has been substantial empirical evidence supporting developmental models and cognitive theories regarding personal epistemology, epistemological beliefs can also be characterized by a set of mostly independent dimensions. This theory, as proposed by Schommer (1990), was the basis of the second paradigm relating education to epistemological theory, as it allowed researchers to speculate that specific, independent beliefs could affect learning. Using existing literature, at first Schommer hypothesized what these dimensions could be, and then, using a factor analysis, he found four significant dimensions. Hofer (2000) performed a similar study based on Schommer's work and refined the definitions of the dimensions, as summarized in Table 1.

Table 1. The dimensions of personal epistemology as summarized by Hofer (2000)

\begin{tabular}{ll}
\hline Dimension & Description \\
\hline Certain/Simple Knowledge & $\begin{array}{l}\text { Whether knowledge is certain and absolute, or } \\
\text { continuously evolving }\end{array}$ \\
Attainability of Truth & $\begin{array}{l}\text { The existence (or non-existence) of absolute truth } \\
\text { Justification for Knowing }\end{array}$ \\
The reasons for learning and/or knowing \\
Source of Knowledge & $\begin{array}{l}\text { Whether knowledge is accepted from an } \\
\text { authoritative source, or reasoned out through } \\
\text { objective and subjective means }\end{array}$ \\
\hline
\end{tabular}

There have been other studies proposing multi-dimensional theories, but they have been generally of a similar nature (Buehl \& Alexander, 2001) and have produced results with only minor points of divergence from Hofer's (2004a) dimensions, so we do not review these studies here.

Integrated models From the developmental and multidimensional models and theories, individuals' personal epistemologies can be understood as evolving through a non-linear and recursive path. However, the field has been dominated by research that adopted a domain-general narrative. In other words, the studies in this area have assumed that the beliefs about knowledge and knowing could be investigated from a generalized perspective, implying that the personal epistemologies of individuals are generally the same across fields (e.g., Baxter Magolda, 1992; Kuhn, 1991). Individuals who held different beliefs about knowledge between varying disciplines were seen as having unsophisticated or underdeveloped viewpoints (Op 't Eynde et al., 2006).

Based on the recognition that disciplinary differences have resulted in different approaches to problem solving and acquisition of knowledge (Alexander, 1992), the possibility of a domain-specific epistemology should not be neglected. Indeed, the institutionalization of these fundamental differences can be seen in most school curricula, where learning typically happens in classes separated by discrete subjects with independent 
content and methods (Op 't Eynde et al., 2006). In this sense, the separation of the sets of resources (such as textbooks and teachers) can lead to a context-dependent model for personal epistemologies, as in the third paradigm mentioned above. The plausibility of a domain-specific approach to epistemology has been the topic of an increasing number of qualitative studies of both a within-subject nature (Schommer et al., 1992) and a betweensubject nature (Liu \& Liu, 2011). Some found that epistemological beliefs tend to be moderately domain-general (Schommer-Aikins, Duell, \& Barker, 2001) whereas others suggested epistemological beliefs to be largely domain-specific (Buehl, Alexander, \& Murphy, 2002).

Summary The discussion about whether personal epistemology can be represented by developmental/cognitive, multidimensional, or integrated models is on-going. Given the empirical evidence supporting all of these models, more than one model may be appropriate for each context. In some cases, an integrated model that combines aspects from various other epistemological models has been suggested. Most commonly, multi-dimensional theorists have claimed that there are developmental components within their various dimensions (Bendixen \& Rule, 2004) and cognitive theorists have suggested that developmental sequences vary by domain (Clinchy, 2002).

\subsection{THE RELATIONSHIP BETWEEN STATISTICAL AND MATHEMATICAL EPISTEMOLOGIES}

Many have suggested that any epistemological interpretation of knowledge may be significantly enhanced by considering the historical context of the knowledge (e.g., Ernest, 1991; Hanson, 1962; Lakatos, 1976). Because there has been very little research on statistical epistemologies, a historical narrative of statistics proved to be informative in designing this research project and analyzing the resulting data.

Statistics as a field of study first began to take shape in the 18th century, when it was used to describe systematically collected census data from various states (Freedman, 2002). In other words, the study of statistics arose out of social and economic needs to understand state demography and make political decisions. The relations between statistics and mathematics, as is now commonly understood, emerged much later, following the development of probability theory (Hald, 1998). Accordingly, it is possible to postulate that, as statistics developed as an academic discipline out of real-world problems and questions, there may be aspects of social context that affect how an individual experiences and approaches statistics. Nonetheless, given that statistics is now inextricably linked to mathematics and the lack of clarity regarding domain-specificity and domain-generality in epistemological research, any discussion on statistical epistemologies that does not mention mathematical epistemologies could run the risk of being incomplete. In that vein, our study sought not only to characterize the personal epistemologies of statisticians in academia (first research question) but also to compare their mathematical and statistical epistemologies (second research question).

There is scarcity of research on the personal epistemologies of academics in mathematics. Nonetheless, some studies have reported on the epistemological perspectives of practicing research mathematicians. For example, Burton and Morgan (2000) created epistemological profiles of various researchers by analyzing the language they used in research publications, and then they corroborated and verified their findings with the academics in interviews. The authors found no discernible patterns between the epistemologies of the research participants. This could be attributed to the constitution of 
their sample, which included a mixture of 35 statisticians, pure mathematicians, and applied mathematicians.

Furthermore, at least as early as the 1980s many studies in both psychology and mathematics education have supported the theory that individuals learn by constructing their own knowledge (e.g., Schoenfeld, 1988, 1989; von Glasersfeld, 1984, 1989). Studies in statistics education (Garfield, 1995; Garfield \& Ben-Zvi, 2007) have also suggested that individuals in statistics learn by constructing knowledge. Thus it would be interesting to see whether the personal epistemologies of statisticians in academic are consistent with constructivist theories of learning.

\section{METHODS}

\subsection{RESEARCH PARTICIPANTS}

Research in statistics education has indicated that statistical misconceptions may be held even by advanced university students and experienced researchers outside of statistics (delMas et al., 2007; King \& Kitchener, 1994). Indeed, Hofer (2001) suggested that a critically aware stance towards knowledge of a field is only really commonplace amongst experienced researchers. To that end, the sample for this research included academics currently researching within the field of statistics.

Six individuals, including three lecturers, one reader, and two professors of statistics each based at one of two leading UK universities, were interviewed for this study. The academic field of statistics covers many different areas with different foci. Moreover, it is commonplace in the UK for researchers in statistics to have completed their taught studies in a subject other than statistics, usually mathematics. The areas of research of the participants, as well as their undergraduate degree and sex, are summarized in Table 2.

Table 2. A summary of the study participants

\begin{tabular}{llll}
\hline Pseudonym & Areas of Research & Undergraduate Degree & Sex \\
\hline S1 & $\begin{array}{l}\text { Applied statistics: Estimation } \\
\text { problems; high-dimensional } \\
\text { statistical inference; statistical } \\
\text { applications }\end{array}$ & Mathematics & Male \\
Theoretical statistics: Markov & Mathematics & \\
Chain Monte Carlo methods; & & Female \\
Bayesian statistics & $\begin{array}{l}\text { Applied statistics: Bayesian } \\
\text { statistics } \\
\text { Theoretical statistics: Non- } \\
\text { parametric statistics; statistical } \\
\text { applications }\end{array}$ & Mathematics & Mathematics \\
S4 & $\begin{array}{l}\text { Applied statistics: Bayesian } \\
\text { statistics; biostatistics } \\
\text { Applied statistics: Medical } \\
\text { statistics }\end{array}$ & Mathematics & Male \\
S5 & & Mathematics, operational research, & Male \\
S6 & statistics, and economics & Male \\
\hline
\end{tabular}

Given the exploratory nature of the study and the small number of participants, it was not possible to ensure sample heterogeneity. Indeed, five of the six participants were male. Although some research has indicated no gender differences in epistemological 
development post-education (Baxter Magolda, 2002; Belenky et al., 1986), the nature of the sample does not allow this issue to be explored. In addition, all of the participants had an academic background in mathematics. Whereas this is commonplace in the UK, not all statisticians come from the same academic background; some may have undergraduate degrees in statistics or other fields, such as psychology or economics. Finally, the number of years of research experience of participants was also not considered when selecting participants, based on the assumption that all post-doctorate researchers in statistics might adopt a personal epistemology that availed to statistical learning. In any case, exploring the possible role of these and other factors (e.g., the cultural and departmental settings) would require a much larger sample and was beyond the scope of the exploratory study reported here.

\subsection{INTERVIEW DESIGN}

The interview protocol for the study was designed and refined over two sets of pilot interviews with seven $\mathrm{PhD}$ candidates from UK universities. The first set of pilot interviews was a series of open discussions with participants in order to develop questions and divide them into groups that would cover each of Hofer's (2000) dimensions of personal epistemology (see Table 1). In addition, based on the fact that the development of epistemology is moderated by personal experiences and interactions with others (e.g., Packer \& Goicoechea, 2000), questions regarding the sociocultural aspects of statistics were included. Finally, given the observed tendency of the participants to compare mathematical and statistical thinking, questions were developed in order to explore more explicitly the relationship between mathematics and statistics.

The second set of interviews revealed two problems that resulted in revisions to the interview protocol. First, in answering a lot of the questions, the participants would often use terms such as "statistical thinking" or "statistician" loosely, and there was a need to disrupt the flow of the conversation to ask them to clarify what they meant. Thus another set of questions was added at the start of the interview to address the meaning of these terms. Second, the participants were unaware of their own views about statistical knowledge, or they appeared to have not discussed them openly to a great extent ever before. Prompting questions to allow the participants to talk about their epistemological beliefs both directly and indirectly were therefore added. The final interview protocol is given in the Appendix.

\subsection{DATA ANALYSIS}

The interviews were transcribed and coded using the dimensions based on Hofer's (2000) description of personal epistemologies as described in Table 1. Each of these dimensions was explored in turn in order to characterize the personal epistemologies of the research participants and address the first research question. In addition, and in order to address the second research question, the data analysis also included a direct exploration of the participants' beliefs about statistical knowledge in relation to other subject areas, notably mathematics. Content analysis was performed and findings were compared to existing literature on personal epistemologies.

In considering which epistemological models may be appropriate to characterize the participants' personal epistemologies (first research question), it was not possible to consider developmental models; as developmental models assume a gradual progression in epistemological development over a period of time (e.g., Moore, 2002; Perry, 1974), previous research on these models has been longitudinal. However, it was possible to assess 
the suitability of a cognitive model for the personal epistemologies of the statisticians interviewed, because the cognitive models maintain the same properties of developmental models, but are assessed by using structured interviews with a standardized evaluation process (King \& Kitchener, 2004). To that end, the interviews conducted in this research included the question: "Can you tell me how your understanding of statistics evolved and developed over time, throughout your education and career?"

The answers to this question were evaluated according to King and Kitchener's (2004) Reflective Judgment Model, which categorizes an individual's reasoning as pre-reflective, quasi-reflective, or reflective, each level representing a deeper understanding of how knowledge is constructed. The suitability of cognitive models and the reflective nature of the participants are discussed in the final part of Section 4.1.

\section{RESULTS}

The report of the results we obtained from analyzing the interviews with the six participants are organized into two sections, each corresponding to one research question.

\subsection{THE PERSONAL EPISTEMOLOGIES OF ACADEMICS IN STATISTICS}

This section addresses the first research question by exploring the main characteristics of the personal epistemologies of the study participants. These characteristics are presented according to Hofer's (2000) four dimensions of personal epistemology as in Table 1: the certainty of knowledge, the justification for knowing, the attainability of truth, and the source of knowledge. The section concludes with a proposal for an integrated model for personal epistemology.

Certainty of knowledge The content analysis revealed that the participants believed that different aspects of statistics could be understood with varying levels of certainty. The participants' beliefs were classified into three categories: objectivism, constructivism, and sociocultural factors. An explanation of these categories and examples that the participants gave are given in Table 3.

Table 3. A summary of the categories under certainty of knowledge

\begin{tabular}{|c|c|c|}
\hline Category & Description & Examples \\
\hline Objectivism & $\begin{array}{l}\text { Described aspects of } \\
\text { statistical knowledge } \\
\text { and statistics that were } \\
\text { interpreted as objective }\end{array}$ & $\begin{array}{l}\text { Mathematics; Logic; Probability Distributions; } \\
\text { Axioms; Proof }\end{array}$ \\
\hline Constructivism & $\begin{array}{l}\text { Described aspects of } \\
\text { statistical knowledge } \\
\text { and statistics that were } \\
\text { interpreted as open to } \\
\text { interpretation or } \\
\text { constructivist in nature }\end{array}$ & $\begin{array}{l}\text { Bayesian topics; Openness; Worthwhile to challenge } \\
\text { knowledge; Limitations to statistical methods; } \\
\text { Different approaches to same problem (choice of } \\
\text { statistical methodology); Conclusions not authoritative; } \\
\text { Interpretation of the problem; Model choice; Model } \\
\text { assumptions }\end{array}$ \\
\hline $\begin{array}{l}\text { Sociocultural } \\
\text { factors }\end{array}$ & $\begin{array}{l}\text { Described statistics and } \\
\text { statistical knowledge } \\
\text { as dependent on social } \\
\text { context }\end{array}$ & $\begin{array}{l}\text { Journalism and media; Trust of statistics; Statistics as a } \\
\text { craft; Statistical problems can have emotional } \\
\text { connotations; Historical context; Interdisciplinary } \\
\text { interactions; Presentation of statistics affected by needs } \\
\text { of audience; Shift of statistical paradigm towards } \\
\text { Bayesian models }\end{array}$ \\
\hline
\end{tabular}


Any mention of objectivism related exclusively to mathematical aspects of statistics having to do with proof, mathematical axioms, and logic, and how they are applied to probability theory. However, belief in absolute truth was always qualified with a reference to the axioms assumed in order for the truth to exist. For example, when discussing about mathematical theories used in statistics, S6 described how these theories are "logically irrefutable" and "always true." Soon afterwards, though, S6 recognized that the theories were derived from "mathematical axioms that are assumed to be true," which would in fact be consistent with constructivism, and not objectivism.

The most dominant aspect within the data was therefore the association of statistics with a constructivist view of knowing; within statistical modelling and inference, each of the participants described statistical knowledge as actively constructed from either mathematics or probability. This was exemplified by S5:

S5 Within statistics...the nature of the knowledge is...true within its own framework, but judgment is needed to decide on its own applicability. Within its own set of axioms, it is objectively true...the crucial thing is whether it is applicable to the situation I'm facing, and that's a subjective judgment.

S5 claimed that knowledge within statistics and mathematics can only be seen as true "within its own set of axioms." To that end, there would be no objective truth within statistics, as any "truth" would only come into existence through engagement with these axioms.

Knowledge was also described as being constructed from the assumptions supposed when making model choices. Whereas proof in mathematics is based on axioms taken to be true, modelling in statistics always starts with assumptions made about data. All of the participants described how the assumptions are pertinent to statistical analysis, and how statistics cannot be objective as a result of these assumptions. S4, for example, claimed that "the assumptions will never be true, it's only about whether they'll be good enough. Because none of the assumptions are true, ever, all statistical analysis is actually formally wrong and incorrect."

Moreover, all of the participants explicitly rejected any notion of absolutism and objectivism within statistics. The apparent potential for misinterpreting a problem, using an unsuitable statistical model, or making inappropriate assumptions, led the participants to recognize the limits of certainty within statistics, and therefore discuss the merits of challenging published knowledge within statistics. A constructivist way of knowing therefore seems representative of the participants.

Through discussing sociocultural aspects of statistics, all of the participants agreed that there was a problem with public trust of statistics, with four of the participants mentioning the issue of trust unprompted and the remaining two explaining the matter after being asked directly. Remarkably, three of the participants exercised the same quote popularized by Mark Twain and Benjamin Disraeli when discussing the issue of trust in statistics: "there are lies, damned lies, and statistics." The quote was mentioned with reference to the fact that members of the public misinterpret statistics frequently, and that, as a result, "good" statisticians view statistics very gingerly. In the words of S1, "statisticians, in my opinion, are a very skeptical bunch." The link made between the public misunderstanding of statistics and individual skepticism of statistical knowledge is an example of how participants' certainty of knowledge may be characterized by radical constructivism, which views knowledge as being adapted to fit a configuration of the social world (e.g., von Glasersfeld, 1984). More specifically, the fact that "good statistical thinking" was related to public trust and misunderstanding of statistics could suggest the suitability of a radical 
constructivist model. However, a full assessment of the relevance of sociocultural factors and the suitability of radical constructivism would need to be to the topic of further research.

Attainability of truth This dimension was used to encompass all data that described the extent to which knowledge in statistics is discovered, constructed, or invented. Two categories used to describe the attainability of truth were assigned at first: constructed and discovered. However, it emerged from the data that it has been possible for many of the participants to become successful within their field without any thought given to the attainability of truth, so a third category called irrelevant was introduced. The descriptions and examples of these categories are given in Table 4 and are discussed in turn below.

Table 4. A summary of the categories under attainability of truth

\begin{tabular}{lll}
\hline Category & Description & Examples \\
\hline Constructed & $\begin{array}{l}\text { Described aspects of statistics } \\
\text { interpreted as being invented } \\
\text { or constructed by the } \\
\text { knower's mind }\end{array}$ & $\begin{array}{l}\text { Data; Axioms; Mathematical statistics; } \\
\text { Assumptions; Statistical framework; Questions } \\
\text { driving statistical work }\end{array}$ \\
Discovered & $\begin{array}{l}\text { Described aspects of statistics } \\
\text { interpreted as an absolute } \\
\text { truth or as having been } \\
\text { "discovered" }\end{array}$ & $\begin{array}{l}\text { Consequences of axioms, questions, and } \\
\text { assumptions; Mathematical statistics; Solutions to } \\
\text { practical problems; Nature of the underlying } \\
\text { sentioned irrelevance of }\end{array}$ \\
& $\begin{array}{l}\text { Menstem not care; Does not matter; Had not thought } \\
\text { Irrelevant } \\
\text { whether knowledge is } \\
\text { constructed or discovered }\end{array}$ & $\begin{array}{l}\text { about it before } \\
\end{array}$ \\
\hline
\end{tabular}

Analogous to the "objective" aspects of statistics described within certainty of knowledge, the viewpoint that knowledge is discovered as absolute truth was limited to mathematical statistics or aspects of statistics that were constructed around mathematics. More precisely, the participants indicated that truth in statistics is limited to a pre-specified statistical framework. To illustrate this, when talking about a specific example relating to drug doses in medical statistics, S6 said:

S6 I could give a result that says a certain dose for these trials is safe for them. I've discovered that result-I've not invented it - that sounds like it's fabricated. I've done it by all the correct methods and followed a set procedure. I may have discovered that $100 \mathrm{mg}$ is the safe dose given my sample, but someone using... different data to inform them might have a different answer, so there are no absolute truths there.

The participants implied that given a set of data with a statistical problem or question, follow-on knowledge can be seen as a discovered truth. For example, with particular reference to S6's question about a safe drug dose, he went on to explain that it would be possible to know absolutely what the sought dose was given a certain data set. Within statistics, then, truth was broadly explained to be constructed or invented, with the absolute truth being referred to as unattainable or non-existent by most of the participants.

There was some disagreement, however, on the subject of construction and "invented" truths within mathematics, with half of the participants arguing that truth in mathematical statistics was constructed and the other half seeing it as absolutely discovered. More strikingly, however, was the tendency to describe this discussion as irrelevant. This could be explained by what was said by two of the participants. For example, on being asked 
about the attainability of truth, S5 responded: "I haven't got a clue! No idea. Don't care." before breaking into laughter. This highlighted that it was possible for S5 to lead a successful academic career in statistics without having put much (or any) thought into the attainability of truth within statistics. S4 also admitted to having "never thought about that." To add to this, S3 noted that different famous statisticians were entitled to have different opinions regarding the attainability of truth to his own, further re-enforcing the idea that the attainability of truth was irrelevant to the participants.

These findings are concurrent with research by Quale $(2008,2012)$ who claimed that ontological consequences of epistemological beliefs can exist subconsciously or independently of the epistemological beliefs themselves. In other words, whether or not the participants thought about the attainability of truth within statistics has not necessarily had an effect on how they learnt statistics and improved as researchers. This potential irrelevance was also perceived by Hofer (2000) who described the emergence of attainability of truth as a central factor in her study as an unexpected finding.

To conclude, although it is clear from the data that there is no absolute attainable truth in statistics and that, through discussion, the participants concluded that most "truths" in statistics are constructed, the relevance of the attainability of truth is probably unimportant to the participants. This is contrary to many of Hofer's studies (2000; Hofer \& Pintrich, 1997) proposing attainability of truth as a dimension of personal epistemology. This could be attributed to the demographic makeup of the research participants, as the participants in Hofer's studies were school-aged students. In this case, we may hypothesize that someone with a mature epistemological stance would understand the attainability of truth to be irrelevant, whereas someone with a naïve stance would have their thoughts influenced by their understanding of the attainability of truth. Future research can examine this hypothesis.

Justification for knowing The third dimension used in the content analysis concerned the justification for knowing - that is, beliefs about what motivates the development of statistical knowledge and why it might be important. Four main reasons transpired from the content analysis: data, problem-driven research, pure intellectual pursuit, and sociocultural motivations. These are discussed in turn below.

The first and most ubiquitous reason was data; each participant mentioned the centrality of data to statistics as well as how data could motivate statistical endeavors. S1, for example, explained that "there are a wide variety of different problems that statisticians are faced with, and these are often as a result of being presented with data." The centrality of and emphasis on data-motivated statistics within the interviews should not be underestimated, as all of the participants also used data to describe their research.

The second justification for knowing that came out of the content analysis emphasized the importance placed on problem-driven research. To illustrate this, when asked about the main characteristics of statistics, S4 said:

S4 To me, statistics starts with the design of an experiment, in which you collect data, and then, developing methods that will help you analyze data. And in the end, applying those methods to interpret and draw connections to the real scientific question that you had before you even began the exercise.

The emphasis here is not on the data itself, but on the collection and subsequent analysis of data that was motivated or influenced by a reality-based problem. The participants gave examples of collaborating with individuals from a wide variety of fields, ranging from astrophysics and medicine to politics and advertising. 
The third justification for knowing was split between applied (S1, S3, S5, and S6) and theoretical statisticians (S2 and S4). Whereas the applied statisticians interviewed placed emphasis on problem-based statistics, the theoretical statisticians placed importance on pure intellectual pursuit, and interest in the study and development of statistics. For example, S3 claimed that "it doesn't matter whether [the statistical] process has applications. It just is interesting in its own right." To add to this, S2 commented that even though "mathematics has traditionally always been a subject that everyone says is beautiful...statistics can be beautiful too!"

The final category within justification for knowing revolved around the sociocultural context of the subject. A lot of the statistical examples that the participants discussed related to a social context of statistics. For example, S2 described how companies selling consumerist goods take advantage of statistics for advertising, as well as the context of statistical applications in the financial sector. Furthermore, S6 explained that "[statistics] is always applying methods to real-world data problems, providing meaningful quantities that people can understand, but also a measure of error around those estimates." The emphasis here should be placed on the fact that $\mathrm{S} 6$ recognizes the relevance of producing "meaningful quantities that people can understand," thereby implicitly acknowledging the social context of statistics.

In order to relate justification for knowing to the theories of personal epistemology, it is helpful to use a social constructivist theory of learning. Three of the four justifications for knowing explained in this subsection (data, problem-driven, and sociocultural reasons) emphasize the importance of the interactions of the participants with their surroundings and social world. In particular, the fact that statistical research was portrayed by all the participants as reality-based is consistent with one of the main principles for social constructivism as set out by Driscoll (2000). The anomaly in the findings is the intrinsic beauty of statistics as a justification for knowing because this interest does not appear to be socially located. It would be unsurprising, however, if this belief was more common amongst participants who are presumably sufficiently interested in statistics to make a career out of it.

Source of knowledge The final dimension examined in the content analysis encompassed all information appertaining to how statistical knowledge is created or discovered, and was labelled source of knowledge. The beliefs of the participants were interpreted to be largely consistent with a constructivist approach to learning with two dominant features: the development of statistical knowledge and the collaborative nature of statistics.

The first of these was described indirectly by all of the participants in response to the question that asked how statistical knowledge developed. For instance, S1 responded:

S1 The traditional way is that people will read published papers and this will result in the improvement of knowledge. As well as this, people go to conferences, give seminars, and knowledge is disseminated in these sorts of ways. Then, from the sort of cutting-edge research articles, people will write research monographs that take important bits from various pieces of research, and synthesize them into a coherent whole that can be read by less of a specialist [audience] than the original researchers. Then there's another kind of agglomeration process where people write textbooks. The most important bits that surface in the monographs will often surface in these textbooks and get taught to graduate students, undergraduates, and so on. There's a sort of filter at every stage....as to what becomes the important stuff for people to know about. 
The responses of the other participants were similar. The process described here is one that satisfies the assumptions behind Lakatos' (1976) heuristic, which describes how, following inter-subjective scrutiny and publication, new knowledge in mathematics goes from being at first tentative and subjective to being internalized as objective knowledge in the eyes of the learner. This can be seen by considering the way in which S1 described an interpolative process of refining knowledge through critique, publication, re-publication, and critique before the knowledge is understood as secure and valuable enough to be published in textbooks as information to be taught to students. Even though the knowledge itself may be constructed from axioms (as discussed in certainty of knowledge and attainability of truth), the knowledge in the textbook is at first internalized as objective by students and other readers (Lynch \& Bogen, 1997). Therefore, because all of the participants agreed that any research after first being published must be subject to criticism before being understood as valuable, it follows that subjective knowledge goes through a reconstructive process to become more objective.

Implicit in Lakatos' heuristic and in a constructivist viewpoint is the second main feature of the source of knowledge, which was the collaborative nature of work and knowledge in statistics, as the nature of submitting work for critique before publishing and re-publishing requires collaboration. Some of the participants recalled working with their peers during school and university, but all of the participants described the importance collaborating with other participants. S5, for example, "strongly believe[d] in statistical training in research that needs to be shared as far of possible," and went as far as saying that "the idea of someone sitting on their own doing statistics is just laughable, especially in a subject that is only really defined in the context of other peoples' work." This was followed by a brief discussion criticizing the way in which statistics was usually taught in an individualistic way in schools.

Although most of the participants spoke positively about collaboration, S2 highlighted how she might have been influenced by her supervisor:

S2 ...you spend three years or whatever doing a $\mathrm{PhD}$, and you're working quite closely with someone who is telling you what to read. Somehow, you're being, without really knowing it...manipulated by your supervisor. So you tend to have very close beliefs to your supervisor...It's always tricky to know whether you are having independent opinions or whether you've been guided on things...it is also influenced by university syllabuses, of course.

In this case, the supervisor could be understood as an authoritative individual who S2 inadvertently took as a source of knowledge, which would be tantamount to the naïve understanding of source of knowledge as outlined by Schommer (1990). It should be clarified, however, that as long as S2 did not take her supervisor's opinion as objective knowledge, then the influence of the supervisor could be understood as an environmental or contextual influence, which would suit well a theory of social constructivism. Indeed, the adoption of Lakatos' heuristic and a collaborative style to learning and working have been described as features of a social constructivist way of knowing (Ernest, 1991, 2011). Moreover, S2 also mentioned how the national or professional context may affect thinking in statistics.

The data organized under this category could have also been appropriately modelled under an epistemological resources paradigm, whereby the basis of statistical knowledge would be understood as a set of context-dependent resources, including peers, published works in statistics, and others. However, further research would be required in order to identify the range of these resources more accurately. 
Searching for an epistemological model: An integrated model Following the exploration of the dimensions of the statisticians' personal epistemologies, it is possible to suggest an integrated epistemological model that could be used to represent their beliefs. Aspects of existing models could be used to represent the views of the statisticians interviewed in this study, though no single model neatly captures the complexity of their beliefs about statistical knowledge.

For example, a multidimensional model, characterized by a set of more-or-less independent dimensions of beliefs, could potentially represent the statisticians' beliefs, but such a model would not fit in well with the fact that the analysis revealed overlaps between different dimensions. The most common overlap was between attainability of truth and other dimensions ( 13 occurrences in total, and at least once by each academic). This raises the question about whether attainability of truth is a mostly-independent dimension of the personal epistemologies recorded. In any case, however, a multidimensional model should not be ruled out completely, as the dimensions other than attainability of truth were moreor-less independent, as per Hofer's (2000) findings.

In considering a cognitive model, all of the participants discussed the development of their beliefs about statistics in one of two manners. The first of these was to offer a generalized narrative that focused on gradual development, as illustrated in the following excerpts:

S2 I think it's been very gradual. I don't think there's been one defining moment... ...little by little, I found links between things that I didn't know were going to be there.

S4 It was definitely very gradual. Coming back to your point, if you go and talk to [my colleague who is not a statistician], he'd give you a very different picture of statistics. What's interesting about statistics is that amongst a group of ten statisticians, not two of them might agree on the right thing to do.

In both instances, the participants perceived their development of knowledge as a gradual process. S2 noted the importance of context on her learning, which is a defining characteristic of King and Kitchener's (2004) reflective thinking. The understanding of the importance of subjectivity and relativity within the subject was indicated by S4 through his comparison of statistics to mathematics. He recognized that different statisticians may have different opinions on the solution to a problem (subjectivity) and the potential disagreement on what might constitute a "good" statistician (subjectivity and relativity). The comparison portrayed mathematics as a less reflective field, but this may be reduced, although the differences may have been heightened by S4 for comparative reasons; this is discussed more in the next section.

The other four participants answered the question by describing discrete events that changed their statistical paradigms. S1 described his master's thesis as central for his intellectual development, whereas S3, S5, and S6 described the learning of Bayesian statistics as pivotal moments. For example, S6 said that:

S6 ...the turning point was when I really started to enjoy mathematics as an undergraduate, and [my lecturer] gave me my first lesson on Bayesian statistics. I couldn't believe there was this new way of thinking...that was the turning point where I got more engaged with my subject...

Given that the development of Bayesian theory made space for a relativity and subjectivity debate in statistics, it is interesting to note that half of the participants mentioned Bayesian statistics as significant to their development. It could be that, by 
creating a space for reflective thought or subjectivism, the learning of Bayesian statistics accommodates more effectively for reflective thought than classical statistics.

It is clear that the first of the approaches described (as adopted by S2 and S4) would affirm a cognitive model for personal epistemology. Whereas the second approach described how the participants reached a reflective stage of judgment, it did not describe how they reached this stage, so it cannot be inferred whether or not a cognitive model would be appropriate in these cases without further evidence. However, by comparing the developmental narratives described by S3, S5, and S6 to the way in which they described public understanding of statistics, it was possible to strengthen the argument for adopting a cognitive model. For example, S5 said:

S5 We have the innumerate using numbers. I've got a real thing about the problems generated by the powerful innumerate, whether it's the media or government or anyone, because the innumerate love numbers. They fetishize them and wave them around, saying "I've got my number and you've got your number," and neither of them have a clue about where it came from or how it's constructed.

S5 here is describing the "innumerate" in a way that can be interpreted as pre-reflective. The key phrase here is how he described the innumerate as not knowing where numbers come from or how they are constructed, because the following discussion then implied that the innumerate individuals have an objective understanding of numbers and statistics. All of the other participants also mentioned how average members of the public were likely to mistrust, misunderstand, or misuse numbers and statistics, reinforcing the idea that the participants recognized that they thought in a more critical and reflective way about statistics than non-statisticians.

To summarize, despite the different research backgrounds of the participants, there were noticeable patterns in the data. It was clear that, as expected, the participants held relativist, constructivist views of statistical knowledge. There was strong evidence to suggest that social constructivism would have been a suitable model, though radical (or cognitive) constructivism could have also been applied within certainty of knowledge. Moreover, the findings seem to be consistent with integrated models of personal epistemologies. In any case, the precise nature of this constructivism would need to be the subject of further research; it would not be appropriate to generalize from such a small convenience sample, not least because of the varying research backgrounds of the participants.

\subsection{STATISTICAL AND MATHEMATICAL EPISTEMOLOGIES}

This section addresses the second research question by investigating the similarities and differences between the participants' beliefs regarding mathematical and statistical knowledge. In order to more fully capture the complex nature of the participants' beliefs, this section opens with an exploration of the structure of the relationship between mathematics and statistics, according to the beliefs of the study participants. Following this, the results are presented according to Hofer's (2000) four dimensions of personal epistemology presented in Table 1: the certainty of knowledge, the justification for knowing, the attainability of truth, and the source of knowledge. We conclude with an argument for the domain specificity of mathematical and statistical personal epistemologies.

The relationship between mathematics and statistics There were two initial reactions to the question asking about the relationship between mathematics and statistics. The first 
of these - expressed by S1, S3, S5, and S6 - was to describe statistics as an independent field with its own theoretical framework and way of thinking. S1, for instance, said he was "very happy with statistics being its own branch with its own characteristics." S5 seemed more surprised by the question, and responded:

S5 First of all, statistics is not part of mathematics. Statistics in its broadest sense is not a subset of mathematics. Maths is an enabling thing of statistics, just as statistics is an enabling technology for other subjects... maths is useful for statistics through probability theory...it's wonderful stuff. But it's not statistics...there are lots of other things to learn apart from that when doing statistics.

These four participants portrayed mathematics as an enabling tool or part of the statistical process. With these four participants (and especially with S5), there was also a sense of adamancy in the answers, suggesting a certainty in their own identities and the role of mathematics in statistics.

The other approach, expressed by S2 and S4, was to initially describe statistics as a part of mathematics. For example, S2 said she was "quite happy for statistics to be mathematics." This was, however, qualified with "...but I'm not sure if you ask a mathematician, they'd say the same thing," followed by an explanation that even if statistics is described as a branch of mathematics, statistics requires a different way of thinking to other areas of mathematics. To illustrate the differences between mathematics and statistics, S4 described the relationship as follows:

S4 Within statistics, there are two components. There's the mathematical component, and the craft component. With the mathematical component, the nature of the knowledge is exactly the same as maths, in the sense that it's true within its own framework, but judgment is needed to decide on its own applicability. Within its own set of axioms, it is objectively true...the crucial thing is whether it is applicable to the situation I'm facing, and that's a subjective judgment [the craft component].

S4 also described statistics as a part of mathematics, though he chose to distinguish statistics by the description of a subjective, "craft" component. The fact that S2 and S4 chose to describe statistics as a part of mathematics could be attributed to the fact that they were both working in theoretical statistics, whereas the other four were involved with more applied research. Alternatively, it may be that the way in which statistics is taught as a subordinate of mathematics could affect the way in which individuals perceive the relationship between mathematics and statistics. Indeed, all but one of the participants (S6) had academic backgrounds in mathematics only. Moreover, S2 noted that although it is uncommon, statisticians may come from non-mathematics backgrounds, and that these individuals might hold different epistemological beliefs to those with a background in mathematics. S1 mentioned that differences in the research culture of different institutions and countries might also influence one's perception of the relationship between mathematics and statistics.

All references to the relationship between mathematics and statistics in the transcripts were tabulated and used to produce Figure 1, which illustrates the relationship between mathematics, probability, statistics, and the real world. Each arrow represents references made by at least two participants indicating the relationship between concepts or disciplines. The direction of the arrow indicates which discipline or concept supports or informs the other. For instance, the real world gives rise to data; pure mathematics is the basis of probability; and so on. Two topics, namely data and probability, were mentioned by all six participants unprompted. As discussed in the literature review, there is a deep 
relationship between mathematics and statistics, although the historical context of this relationship was only highlighted by S5.

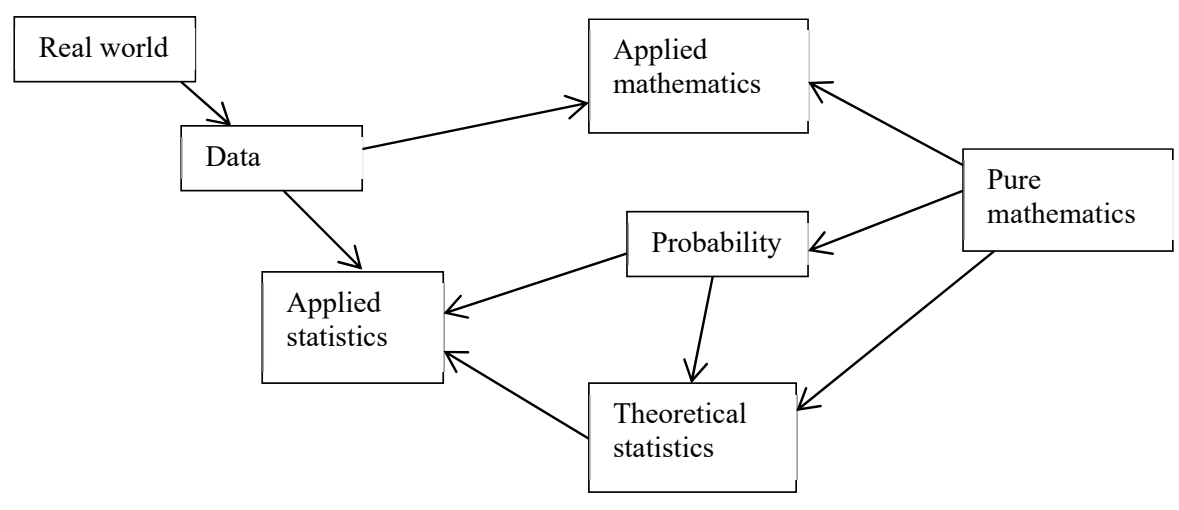

Figure 1. Participants' beliefs about how statistics is related to mathematics via probability

Certainty of knowledge Notwithstanding the uncertainty of the relationship between statistics and mathematics as portrayed by the participants, it was still possible to make comparisons between the epistemologies attached to these subjects for each of the dimensions mentioned in the answer to the first research question. Regarding certainty of knowledge, all of the participants described differences between mathematics and statistics when it came to this dimension. The viewpoint that was ubiquitous amongst the participants can be illustrated by S4's discussion of the differences between statistics and mathematics:

S4 ...statistics does branch away from maths in some sense...there is no right or wrong answer, obviously...I would rather say that statistics is not so rigorous as mathematics. But you can still get answers that are more deeply meaningful than if you are stricter or more rigorous.

S4 highlighted the differences between personal epistemologies in the two subjects; mathematics is taken as more "rigorous" or objective. S1 also highlighted objective qualities of mathematics:

S1 Even in the purest of mathematics, you make definitions and you ask yourself what are the consequences of the definitions given the axioms that you impose...given definitions made, the logical consequences of those definitions are absolute, and under the axioms of logic that mathematics uses. In that sense, you could say that I see mathematics objectively.

Whereas S1 explicitly refers to objectivism, it is possible to suggest that his account also has some constructivist aspects; the absoluteness within mathematics is described to be dependent upon the axioms, which were later labelled by S1 as "invented, as opposed to discovered." In other words, even though the participants were quick to talk about objective qualities of mathematics, it was clear that they held constructivist epistemologies in this regard.

The type of constructivism applied to the certainty of knowledge within mathematics, however, seemed to be a possible point of divergence from the statistical epistemologies of the participants. With respect to statistics, a constructivist way of understanding was deemed appropriate, whereas within mathematics, no mention was made of how their 
understanding of mathematics could adapt to fit the world. To the contrary, all of the participants made comments that could imply that individuals change their observed configuration of the world in order to understand mathematical constructions.

Attainability of truth The most common way in which this dimension was addressed was to make a comparison based on the structure of mathematics and statistics. In particular, most of the participants compared the attainability of truth in pure mathematics to that in probability and theoretical statistics, and attainability of truth in applied mathematics to that in applied statistics. These comparisons were usually made separately. For instance, to relate pure mathematics to theoretical statistics, S1 said:

S1 I would have thought that the more you move towards pure mathematics, the more you are discovering and the less you are inventing...only at the theoretical end [of statistics] is one looking to prove theorem. If you prove a theorem, it has the safe logical correctness as proof in mathematics. There's no difference.

At the other end of the spectrum, when asked whether knowledge in mathematics was discovered or invented, S6 responded:

S6 I was about to say perhaps in some realms of applied mathematics, but that could be statistics! So in pure mathematics, I'd say no. Ideally, pure mathematics should be as objective as possible, and that's a distinction from applied statistics.

However, S5 did concisely encompass most of the areas of mathematics and statistics together when discussing the nature of truth within the disciplines:

S5 ...you need to distinguish from different sorts of maths as well, like pure maths and applied maths. There is very little difference between thinking probability theory and pure maths...[but] applied mathematicians have to think differently. They do some proofs and mathematical stuff, but some of them actually need to think about what applies in the real world, and then it becomes a craft issue. Then it becomes very similar to statistics, because they need to ask themselves whether their assumptions fit the real world. The only difference is that the applied mathematicians don't tend to have stochastic elements to their conclusions.

In short, similarities in attainability of truth between mathematics and statistics were made between appropriate sub-disciplines of each subject. To that end, as with the statistical epistemologies of the participants, the limits of the relevance of the attainability of truth within mathematics were also explained by three of the participants (S3, S4, S5), with S5 saying that the only difference being that "statisticians use probability and will have a stochastic element to their work." He then went on to explain that as with his opinion on statistics, the attainability of truth was something that did not matter to him.

It should be noted that the participants' opinions about knowledge in mathematics were expressed differently in the different parts of the interview. Specifically, in the sections of the interview which focused primarily on statistics, it was more usual for mathematics to be portrayed as discovered truth and infallible, whereas in the section of the interview that asked specifically about mathematics, more considered, in depth thoughts about mathematics were offered. Kvale (1996) discussed this phenomenon, explaining that individuals often use stronger language when asked to make direct comparisons. These discrepancies were taken into account during the content analysis. 
Justification for knowing Within statistics, four main justifications for knowing statistics emerged from the analysis - data, problem-driven motivation, sociocultural, and intrinsic beauty - with particular emphasis placed on the first three. Within mathematics, these categories were also appropriate to the interviews, albeit with different emphases. Whereas data, problem-driven, and sociocultural reasons were mentioned by the participants (mentioned twice, twice, and thrice respectively by three participants), intrinsic beauty was given higher prominence as a justification for knowing (mentioned nine times by five participants). To illustrate the importance of the intrinsic beauty of mathematics, S6 said:

S6 Mathematics has traditionally always been a subject that everyone says is beautiful... Statistics can be beautiful too if derived from pure mathematics, but a lot of the times it can be ugly with messy formulae. But in mathematics there's not always a direct focus, and a lot of people are looking at things for pure enjoyment, rather than looking for something useful or helpful.

Importance was placed on the fact that mathematics, unlike statistics, is less likely to need a "direct focus," and that people may be doing mathematics for "pure enjoyment." Even though S6 recognized that "statistics can be beautiful too," his statement put relatively more focus on the intrinsic beauty of mathematics.

There were also four instances where three of the participants interviewed placed relatively less importance on sociocultural justifications for knowing mathematics. In one case, after explaining that statisticians need to understand the context of their work or statistics, S1 was asked whether he thought this was the case in mathematics. He responded:

S1 Rarely, I mean there are various subjects like mathematical biology that are studied in applied maths...but I don't know whether they'd call that mathematics.

In the preceding dialogue, $\mathrm{S} 1$ explained that the main reason mathematics requires less context is because there are objectively correct consequences of mathematical axioms if logic is used correctly. Tied into this is the fact that everyone except S4 also implied that questions and problems are much less likely to motivate problems in mathematics.

The consequence of sociocultural-driven, problem-driven, and data-driven reasons for studying mathematics being less prominent is that, with the participants, the case for social constructivism in mathematics is much less strong than that for social constructivism in statistics. This is because, by emphasizing the role of the intrinsic beauty of mathematics as a reason for studying it, the participants downplayed the role of the interaction of mathematics with their surrounds and social world. These findings appear to contrast with the work of Ernest $(1991,2011)$ that suggests social constructivism has a central role in mathematical epistemologies. However, because the evidence is very case-specific, further investigation is required. Moreover, Ernest's work focused on the epistemological beliefs of students - not of academics - thereby offering a possible reason for the discrepancy.

Source of knowledge Within statistics, two factors were of consequence. The first of these, Lakatos' (1976) heuristic, described the process of internalization of statistical knowledge through publication. No noteworthy comparisons regarding Lakatos' heuristic were made with regard to mathematics, so even if the participants believed they acquired mathematical knowledge in the way that Lakatos described, it was not possible to infer this from the data. The relevance of Lakatos' heuristic to mathematics would need to be the subject of further study. 
Nonetheless, the second observed source of knowledge for the statistical epistemologies - collaboration with others - was mentioned as important in mathematics by three of the participants. S1, for instance, mentioned the collaboration between mathematicians and theoretical physicists, S2 mentioned biologists, and S3 talked about mathematics in astronomy. Moreover, what S2 implied about how supervisors and teachers can influence personal epistemologies may also apply to mathematics, as her argument did not refer to a statistical context in particular. It should be noted, however, that S1 suggested he "would've thought the collaborations with scientific fields would be much less, and much less wide-ranging" in mathematics than in statistics, bringing into question the extent to which collaboration was viewed as a source of knowledge for mathematics.

In brief, there was a lack of data regarding the sources of knowledge in mathematics, so the content analysis did not allow for substantive comparisons to be made in this area. Instead, the similarities and differences noticed in the research conducted for this paper could be used as an indication that further study in this area may be fruitful and of interest to educational researchers.

Summary The main similarities and differences between the statistical and mathematical epistemologies of the participants, and hence the findings for the second research question, are summarized in Table 5 according to each of Hofer's (2000) dimensions of personal epistemology. For completeness, a summary of the relationship between mathematics and statistics according the data from this study is also included in Table 5. Given the comparisons made in answering this question, and in particular given the multifaceted relationship between mathematics and statistics, it is possible to add to the domain-specificity/domain-generality discourse in epistemological research that was highlighted by Op 't Eynde et al. (2006). The data alone highlighted some differences between the mathematical and statistical epistemologies of the interviewees, thereby supporting the domain-specific argument; the domain-general argument would require more inter-disciplinary congruence between the personal epistemologies discussed in this research. In addition, the described relationship between mathematics and statistics indicated that the participants view the two subjects, although strongly related, as separate entities, thus strengthening the argument to consider the relevance of domain-specificity. To conclude, comparing the mathematical and statistical epistemologies of statistics academics is a substantive research task that deserves its own study that can add to the growing literature in inter- and intra-disciplinary epistemological research. It would be of particular importance to consider the discussion on the structure of the two subjects, and whether the findings from this paper suggest it would be more appropriate to consider pure and applied mathematics, probability, and all branches of statistics to be investigated together or separately.

Table 5. Similarities and differences between the mathematical and statistical personal epistemologies of the participants in this study

\begin{tabular}{ll}
\hline Dimension & Comparison \\
\hline Certainty of & $\begin{array}{l}\text { The participants alluded to constructivist ways of understanding both } \\
\text { knowledge } \\
\text { important for the development of statistical epistemologies when } \\
\text { compared to mathematical epistemologies. }\end{array}$ \\
\hline
\end{tabular}




\begin{tabular}{ll}
\hline Attainability of truth & $\begin{array}{l}\text { Parallels were drawn between pure mathematics and theoretical } \\
\text { statistics, and applied mathematics and applied statistics. As with } \\
\text { statistical epistemologies, the participants seemed to be unworried by } \\
\text { the properties of this dimension. }\end{array}$ \\
Justification for & $\begin{array}{l}\text { Much more emphasis was placed on intrinsic beauty of mathematics as } \\
\text { a justification for knowing than in statistics. Unlike within statistics, } \\
\text { social constructivism appears to be less relevant to the mathematical } \\
\text { personal epistemologies of the participants. }\end{array}$ \\
Source of knowledge & $\begin{array}{l}\text { Mathematics was described as a collaborative subject, but not to the } \\
\text { same extent as statistics. Further study is needed. }\end{array}$ \\
The relationship & $\begin{array}{l}\text { Real world problems and observations give rise to data, which is used } \\
\text { between mathematics } \\
\text { and statistics }\end{array}$ \\
& $\begin{array}{l}\text { in applied statistics and mathematics. Tools developed in pure } \\
\text { mathematics are necessary in probability and theoretical statistics, } \\
\text { which form the backbone of applied statistics. }\end{array}$ \\
\hline
\end{tabular}

\section{CONCLUSION}

The driving force behind this investigation was to offer insight into what set of epistemological beliefs would be most availing to statistical learning and for reducing misconceptions in statistics. Going by the results presented above, it seems that experts in statistics adopt constructivist views of their field and tend to distinguish their beliefs about statistical knowledge from mathematical knowledge. However, before establishing the epistemological aims for students in statistics, it will be necessary to expand on the present study. In particular, the results in this paper could be used to design an epistemological questionnaire for administration to a larger sample, which will be necessary in order to improve validity, particularly given the exploratory nature of the present study, the small number of participants, and the relative homogeneity of the sample. In particular, it is worth noting all of the participants came from mathematics, which might have generated some bias in the results because, in practice, statisticians come from a wide variety of academic backgrounds. In addition, the results highlighted potential epistemological differences between statisticians of different specialties, another possible topic for future research.

There is also the opportunity to use the results to help complement research in statistical thinking. Pfannkuch and Wild, for example, have published several studies concerning the thought processes of professional statisticians (e.g., Pfannkuch \& Wild, 2000; Wild \& Pfannkuch, 1999), aiming to uncover elements of applied statistical practice and statistical thinking for the use of teachers of statistics. Some of the findings from this paper may contribute to the discussion on the importance of "variation" within statistical thinking (Wild \& Pfannkuch, 1999), or to the discussion on the development towards teaching of the "art" of statistics (Pfannkuch \& Wild, 2000). Although it is important to distinguish between statistical epistemologies and statistical thinking, some of the findings in this paper may inform research in statistical thinking, which up until this point has been quite limited.

The results in the paper allow the formulation of a hypothesis about what makes statistics so prone to student (and indeed, teacher) misconceptions. Traditionally, students' access to statistics education has at times been limited and postponed until the upper school years, and once students have been introduced to it, learning of the subject has often been part of their learning of mathematics. The results from this study suggest that this approach to teaching statistics may be problematic. Teaching statistics as a sub-domain of mathematics may ignore important epistemological differences between the two disciplines 
and may lead to the students applying mathematical epistemologies that may be unavailing for statistical learning.

To that end, curricula that include contextualized learning for statistics and incorporate research- and inquiry-based learning could be pursued in order to reduce statistical misconceptions (e.g., Burrill \& Biehler, 2011; Paton, 1990); the findings of this paper are consistent with the recommendations to move towards contextualized learning. Such programming and initiatives have been implemented in Israel (Ben-Zvi, Gil, \& Apel, 2007), the USA (Franklin et al., 2007; Lesser \& Pearl, 2008), New Zealand (New Zealand Ministry of Education, 2007), and other countries. Therefore, given the persistence of statistical misconceptions among students (Garfield \& Ben-Zvi, 2007), a lack of contextualized learning alone is not sufficient to explain the challenges in improving statistics education.

One possible explanation could be found in considering the statistical epistemologies of teachers. Indeed, statistical misconceptions can be appropriated and compounded by the fact that teachers of statistics themselves may apply mathematical epistemologies to statistics (Bargagliotti \& Franklin, 2015), thus potentially leading students astray from the offset. It would also explain why statistics instruction has even occasionally been recorded to have negative effect on certain topics of conceptual understanding (delMas et al., 2007). Thus, where contextualized learning may be an effective manner to develop the desired epistemological beliefs that are most availing to statistical thought and learning, it will be ineffective unless the teachers hold such beliefs about statistics.

In this respect, by bringing together the fields of epistemological research, statistics education, and statistical understanding, this paper contributes to the issue of how an understanding of epistemic beliefs can improve teaching and learning in both statistics and mathematics. Moreover, the comparison between mathematical and statistical epistemologies allowed for the argument presented of the domain-specificity of statistics and mathematics, thereby contributing to the ongoing debate of the generalizability of personal epistemologies (Op 't Eynde et al., 2006; Schommer-Aikins et al., 2001). As the field gains a better understanding of what productive thinking about statistics involves, like in the study of experts' epistemologies of statistics, significant implications for statistics education can follow.

\section{REFERENCES}

Alexander, P. A. (1992). Domain knowledge: Evolving themes and emerging concerns. Educational Psychologist, 27(1), 33-51.

Bargagliotti, A., \& Franklin, C. (2015). The statistical education of teachers: Preparing teachers to teach statistics. CHANCE, 28(3), 19-27.

Baxter Magolda, M. B. (1992). Knowing and reasoning in college: Gender-related patterns in students' intellectual development. San Francisco, CA: Jossey-Bass.

Baxter Magolda, M. B. (2002). Epistemological reflection: The evolution of epistemological assumptions from age 18 to 30. In B. K. Hofer \& P. R. Pintrich (Eds.), Personal epistemology: The psychology of beliefs about knowledge and knowing (pp. 89-102). Mahwah, NJ: Erlbaum.

Belenky, M., Clinchy, B. M., Goldberger, N., \& Tarule, J. (1986). Women's ways of knowing: The development of self, voice, and mind. New York: Basic Books.

Bendixen, L. D., \& Rule, D. C. (2004). An integrative approach to personal epistemology: A guiding model. Educational Psychologist, 39(1), 69-80. 
Ben-Zvi, D. (2004). Reasoning about data analysis. In D. Ben-Zvi \& J. B. Garfield (Eds.), The challenge of developing statistical literacy, reasoning, and thinking (pp. 121-146). Dordrecht, The Netherlands: Kluwer.

Ben-Zvi, D., Gil, E., \& Apel, N. (2007). What is hidden beyond the data? Helping young students to reason and argue about some wider universe. Paper presented at The Fifth International Research Forum on Statistical Reasoning, Thinking, and Literacy (SRTL5), University of Warwick, UK.

Buehl, M. M., \& Alexander, A. A. (2001). Beliefs about academic knowledge. Educational Psychology Review, 13(4), 385-418.

Buehl, M. M., Alexander, P. A., \& Murphy, P. K. (2002). Beliefs about schooled knowledge: Domain specific or domain general. Contemporary Educational Psychology, 27(3), 415-449.

Burrill, G., \& Biehler, R. (2011). Fundamental statistical ideas in the school curriculum and in training teachers. In C. Batanero, G. Burrill, \& C. Reading (Eds.), Teaching statistics in school mathematics. Challenges for teaching and teacher education: A Joint ICMI/IASE Study (pp. 57-69). Dordrecht, The Netherlands: Springer.

Burton, L., \& Morgan, C. (2000). Mathematicians writing. Journal for Research in Mathematics Education, 31(4), 429-453.

Castro Sotos, A. E., Vanhoof, S., Van den Noortgate, W., \& Onghema, P. (2007). Students' misconceptions of statistical inference: A review of the empirical evidence from research on statistics education. Educational Research Review, 2(2), 98-113.

Chance, B., delMas, R., \& Garfield, J. (2004). Reasoning about sampling distributions. In D. Ben-Zvi \& J. Garfield (Eds.), The challenge of developing statistical literacy, reasoning, and thinking (pp. 295-323). Dordrecht, The Netherlands: Kluwer.

Clinchy, B. M. (2002). Revisiting women's ways of knowing. In B. K. Hofer \& P. R. Pintrich (Eds.), Personal epistemology: The psychology of beliefs about knowledge and knowing (pp. 63-87). Mawhwah, NJ: Erlbaum.

Confrey, J., \& Kazak, S. (2006). A thirty-year reflection on constructivism in mathematics education in PME. In A. Gutiérrez \& P. Boero (Eds.), Handbook of research on the psychology of mathematics education: Past, present, and future (pp. 305-347). Rotterdam, The Netherlands: Sense Publishers.

delMas, R., Garfield, J., Ooms, A., \& Chance, B. (2007). Assessing students' conceptual understanding after a first course in statistics. Statistics Education Research Journal, $6(2), 28-58$.

[Online: http://iase-web.org/documents/SERJ/SERJ6(2)_delMas.pdf]

delMas, R., \& Liu, Y. (2005). Exploring students' conceptions of the standard deviation. Statistics Education Research Journal, 4(1), 55-82. [Online: http://iase-web.org/documents/SERJ/SERJ4(1)_delMas_Liu.pdf]

Driscoll, M. P. (2000). Psychology of learning for instruction (2nd ed.). Boston, MA: Allyn \& Bacon.

Ernest, P. (1991). The philosophy of mathematics education. Basingstoke, UK: The Falmer Press.

Ernest, P. (2011). The psychology of learning mathematics. Saarbrücken, Germany: LAP LAMBERT Academic Publishing.

Finch, S., \& Cumming, G. (1998). Assessing conceptual change in learning statistics. In L. Pereira-Mendoza, L. Seu Kea, T. Wee Kee, \& W. K. Wong (Eds.), Proceedings of the Fifth International Conference on Teaching Statistics (pp. 897-904). Voorburg, The Netherlands: International Statistical Institute.

Franklin, C., Kader, G., Mewborn, D., Moreno, J., Peck, R., Perry, M., \& Scheaffer, R. 
(2007). Guidelines for assessment and instruction in statistics education (GAISE) report. Alexandria, VA: American Statistical Association.

Freedman, D. (2002). From association to causation: Some remarks on the history of statistics. Technical Report, University of California, Statistics Department, Berkeley.

Garfield, J. (1995). How students learn statistics. International Statistical Review, 63(1), $25-34$.

Garfield, J., \& Ben-Zvi, D. (2007). How students learn statistics revisited: A current review of research on teaching and learning statistics. International Statistical Review, 75(3), 372-396.

Hald, A. (1998) A history of mathematical statistics. New York: Wiley.

Hammerman, J. K., \& Rubin, A. (2004). Strategies for managing statistical complexity with new software tools. Statistics Education Research Journal, 3(2), 17-41.

[Online: http://iase-web.org/documents/SERJ/SERJ3(2)_Hammerman_Rubin.pdf]

Hanson, R. (1962). The irrelevance of history of science to philosophy of science. The Journal of Philosophy, 59(4), 574-586.

Helmer, O., \& Rescher, N. (1959). On the epistemology of the inexact sciences. Management Science, 6(1), 25-52.

Hofer, B. (2000). Dimensionality and disciplinary differences in personal epistemology. Contemporary Educational Psychology, 25(4), 378-405.

Hofer, B. (2001). Personal epistemology research: Implications for learning and teaching. Journal of Educational Psychology Review, 13(4), 353-383.

Hofer, B. (2004a). Exploring the dimensions of personal epistemology in differing classroom contexts: Student interpretations during the first year of college. Contemporary Educational Psychology, 29(2), 129-163.

Hofer, B. (2004b). Introduction: Paradigmatic approaches to personal epistemology. Educational Psychologist, 39(1), 1-3.

Hofer, B. K., \& Pintrich, P. R. (1997). The development of epistemological theories: Beliefs about knowledge and knowing and their relation to learning. Review of Educational Research, 67(1), 88-140.

King, P. M., \& Kitchener, K. S. (1994). Developing reflective judgment: Understanding and promoting intellectual growth and critical thinking in adolescents and adults. San Francisco, CA: Jossey-Bass.

King, P. M., \& Kitchener, K. S. (2004). Reflective judgment: Theory and research on the development of epistemic assumptions through adulthood. Educational Psychologist, 39(1), 5-18.

Konold, C. (1989). Informal conceptions of probability. Cognition and Instruction, 6(1), 59-98.

Konold, C. (1991). Understanding students' beliefs about probability. In E. von Glasersfeld (Ed.), Radical constructivism in mathematics education (pp. 139-156). Dordrecht, The Netherlands: Kluwer Academic Publishers.

Kuhn, D. (1991). Skills of argument. Cambridge, UK: Cambridge University Press.

Kvale, S. (1996). InterViews: An introduction to qualitative research writing. London: SAGE Publications.

Lakatos, I. (1976). Proofs and refutations. Cambridge, UK: Cambridge University Press.

Lesser, L. M., \& Pearl, D. K. (2008). Functional fun in statistics teaching: Resources, research, and recommendations. Journal of Statistics Education, 16(3), 1-11. [Online: http://ww2.amstat.org/publications/jse/v16n3/lesser.pdf]

Liu, P. H., \& Liu, S. Y. (2011). A cross-subject investigation of college students' epistemological beliefs of physics and mathematics. The Asia-Pacific Education Researcher, 20(2), 336-351. 
Lynch, M., \& Bogen, D. (1997). Sociology's asociological "core": An examination of textbook sociology in light of the sociology of scientific knowledge. American Sociological Review, 62(3), 481-493.

Meletiou-Mavrotheris, M., \& Lee, C. (2002). Teaching students the stochastic nature of statistical concepts in an introductory statistics course. Statistics Education Research Journal, 1(2), 22-37.

[Online: http://iase-web.org/documents/SERJ/SERJ1(2).pdf]

Moore, W. S. (2002). Understanding learning in a postmodern world: Reconsidering the Perry scheme of intellectual and ethical development. In B. K. Hofer \& P. R. Pintrich (Eds.), Personal epistemology: The psychology of beliefs about knowledge and knowing (pp. 17-36). Mahwah, NJ: Erlbaum.

Muis, K. R. (2004). Personal epistemology and mathematics: A critical review and synthesis of research. Review of Educational Research, 74(3), 317-377.

New Zealand Ministry of Education. (2007). The New Zealand Curriculum: Mathematics and statistics.

[Online: http://nzcurriculum.tki.org.nz/]

Olsen, W., \& Morgan, J. (2005). A critical epistemology of analytical statistics: Addressing the sceptical realist. Journal for the Theory of Social Behaviour, 35(3), 255-284.

Op 't Eynde, P., De Corte, E., \& Verschaffel, (2006). Epistemic dimensions of students' mathematics-related belief systems. International Journal of Educational Research, 45(1), 57-70.

Pajares, F. (1992). Teachers' beliefs and educational research: Cleaning up a messy construct. Review of Educational Research, 62(3), 307-332.

Packer, M. J., \& Goicoechea, J. (2000). Sociocultural and constructivist theories of learning: Ontology, not just epistemology. Educational Psychologist, 35(4), 227-241.

Paton, R. (1990). Can statistics be rescued from mathematics? Teaching Statistics, 12(3), 66-69.

Perry, W. G. (1970). Forms of intellectual and ethical development in the college. New York: Holt, Rinehart \& Winston.

Perry, W. G. (1974). Students as makers of meaning. Harvard University. Boston, MA: Annual report of the Bureau of Study Counsel.

Pfannkuch, M., \& Wild, C. J. (2000). Statistical thinking and Statistical practice: Themes gleaned from professional statisticians. Statistical Science, 15(2), 132-152.

Piaget, J. (1972). Psychology and epistemology: Towards a theory of knowledge. Harmondsworth, UK: Penguin.

Quale, A. (2008). Radical constructivism: A relativistic epistemic approach to science education. Rotterdam, The Netherlands: Sense.

Quale, A. (2012). On the role of constructivism in mathematical epistemology. Constructivist Foundations, 7(2), 104-111.

Reading, C., \& Shaughnessy, J. M. (2004). Reading about variation. In D. Ben-Zvi, \& J. Garfield (Eds.), The challenge of developing statistical literacy, reasoning, and thinking (pp. 201-226). Dordrecht, The Netherlands: Kluwer.

Schoenfeld, A. H. (1988). When good teaching leads to bad results: The disasters of "welltaught" mathematics courses. Educational Psychologist, 23(2), 145-166.

Schoenfeld, A. H. (1989). Explorations of students' mathematical beliefs and behavior. Journal for Research in Mathematics Education, 20(4), 338-355.

Schommer, M. (1990). Effects of beliefs about the nature of knowledge on comprehension. Journal of Educational Psychology, 82(3), 498-504.

Schommer, M. (1998). The influence of age and education on epistemological beliefs. British Journal of Educational Psychology, 68(4), 551-563. 
Schommer, M., Crouse, A., \& Rhodes, N. (1992). Epistemological beliefs and mathematical text comprehension: Believing it is simple does not make it so. Journal of Educational Psychology, 84(4), 435-443.

Schommer-Aikins, M., Duell, O. K., \& Barker, S. A. (2001, April). Domain generality of epistemological beliefs: It is a matter of degree. Paper presented at the Annual Meeting of the American Educational Research Association. Seattle, WA.

Sedlmeier, P. (1999). Improving statistical reasoning: Theoretical models and practical implications. Mahwah, NJ: Erlbaum.

Shaughnessy, J. M. (2003). Research on students' understanding of probability. In J. Kilpatric, W. G. Martin, \& D. Schifter (Eds.), A research companion to principles and standards for school mathematics (pp. 216-226). Reston, VA: National Council of Teachers of Mathematics.

von Glasersfeld, E. (1984). An introduction to radical constructivism. In P. Watzlawick (Ed.), The invented reality (pp. 17-40). New York: Norton.

von Glasersfeld, E. (1989). Cognition, construction of knowledge, and teaching. Synthese, 80(1), 121-140.

Wild, C. J., \& Pfannkuch, M. (1999). Statistical thinking in empirical enquiry. International Statistical Review, 67(3), 223-265.

AUREL H. DIAMOND

The Federmann School of Public Policy and Government

The Hebrew University of Jerusalem Mount Scopus, Jerusalem 9190501, Israel aurel.diamond@mail.huji.ac.il 


\section{APPENDIX}

\section{The Interview Protocol}

Introduction and Definitions

- In your opinion, what are the main characteristics of statistics?

o Name some characteristics of your branch of statistics.

- How would you describe "statistical thinking"?

o How do you perceive the "statistical process"? What is the procedure involved in doing statistics?

- In your opinion, what is a statistician?

o How do you perceive yourself as a statistician?

Justification for Knowing and Attainability of Truth

- Some hold that solving problems in statistics is a thinking activity involving personal creativity. Others argue that solving the problems requires following predetermined, known procedures. What is your opinion about this? Why? (modified from Liu \& Liu, 2011, pp. 341-342)

o Can you give some examples? Do you think that this is an objective or subjective process? Or somewhere in between?

- In your opinion, what are the similarities and differences between statistics, art, and philosophy? (modified from Liu \& Liu, 2011, pp. 341v342)

\section{Certainty of Knowledge and Source of Knowledge}

- How does statistical knowledge develop?

o How do researchers work?

- Would you say research in statistics is mainly an individual or a collective process?

- Some claim that statistical knowledge is discovered absolute truth, yet others argue that such knowledge is invented or constructed by our minds. What is your opinion about this? (modified from Liu \& Liu, 2011, pp. 341-342)

o Why? Please defend your answer with examples.

- Can there be absolute or objective knowledge in statistical research?

o Do you think that published knowledge in statistics should go unchallenged?

Relationship Between Mathematics and Statistics

- We just discussed some of the objective and subjective qualities of statistics. How do you think this compares to mathematics?

- What is your understanding of the relationship between mathematics and statistics?

o How do mathematics and statistics inform each other as subjects?

- In your understanding, what are the similarities and differences between mathematical and statistical thinking? If possible, please explain your answer with examples.

- Do statisticians need to be able to think mathematically in order to conduct their research? How do you think when you are conducting research or solving a problem in your field? How do you think this compares to the way a mathematician thinks when they are solving a problem or conducting research?

\section{$\underline{\text { Sociocultural Aspects }}$}

- How do you think statistics is perceived by various groups and members of the public?

o From your experiences, how would you say that these people relate to statistics?

- How does this compare to the way mathematics is perceived and experienced by the public?

- Can you tell me how your understanding of statistics evolved and developed over time throughout your education and career? 